\title{
Endurance of the wooden bridge reinforced by the dowel plates
}

https://doi.org/10.2478/sgem-2018-0023

received June 1, 2018; accepted September 3, 2018.

Abstract: The most important piece of road infrastructure is bridges. Wooden bridges have advanced constantly during the past decades. The trend began in Scandinavian countries but has also now gained significant ground in Russia. This research studies experimental endurance potential of the joints of the wooden beam while considering the coefficient of asymmetry of the cycle, which corresponds to the actual operating conditions. Performance analysis of the composite bars is carried out based on the experiment; the development of a special methodology for calculating the joints of wooden elements with the dowel plates for their better endurance is also introduced in this paper. The results of experimental studies on the performance of bending composite wooden bridge bars based on dowel plates operating under cyclic influences thus determine the endurance limit of wood for composite wooden bridge beams based on dowel plates. The calculation technique and interdependence of the endurance coefficient affecting the asymmetry coefficient of the bent composite wooden bridge bars on the dowel plates under cyclic loading are considered. The experimental data on the endurance of composite wooden bridge beams have been obtained, and separate analysis has been made of the compounds under cyclic loading performance; a method has been developed for calculating the bent composite wooden bridge bars reinforced by the dowel plates under cyclic influences.

Keywords: road infrastructure; railway; fatigue; number of loads.

\section{Introduction}

Bridges are traditionally built using stones, concrete or steel [1]. Wood could substitute a few of these materials mainly due to its low weight ratio compared to its high endurance [2]. Bridges in wood often attract attention due to their creative design and structure, the ability to assemble them in record time and their interesting economic and functional efficiency. The technical requirements for all types of bridges constructed using all materials have already been standardized [3]. Despite that forest resources can provide interesting economic benefits, the dark point of the wooden bridge technology is that it uses a raw material often worldwide contested. The heavy deforestation threatens the natural and physical environments [4-9]. Nobody knows exactly how much of the forests have already been destroyed, but many scientists around the world have proved that ground movements destroy a huge area of forests [1017]. Drought and climate changes also contribute to their degradation [18-20]. In addition of the conversion of forest land to agricultural or urbanized terrain. The compensatory solution consists of the plantation of trees established primarily for timber production. The Russian Federation, Brazil, Canada, the United States and China are the most forest-rich countries accounting to $53 \%$ of the global forest area. The Russian Federation suffers from a lack of connectedness between many of its regions. One of the most challenging tasks is to ensure communication between different parts of their vast domain and transport in the entire Russian territory. This encouraged us to deal with this problem. In addition, this country is crossed by 2.8 million rivers and has 72,500 roads and rail bridges, 1/9 of which are built of wood (Fig. 1).

Owing to their low bulk weight, high relative strength (i.e. design resistance vs. density of the material) and resistance to weathering; the wooden structures are currently widely used in construction [21]. In recent years, glued wooden structures have been usually used in the Russian Federation [22]. However, in some areas, exfoliations of glued joints within the building structures have been identified [23]. The use of glue sleepers and
*Corresponding author: Fakhridine Boymatov, Faculty of Building Structures, Grounds and Foundations Constructions, Voronezh State Technical University, Russia, E-mail: boymatov64@mail.ru Lamri Dahoua: Department of Road Construction and Maintenance, National Transport University, Kiev, Ukraine 

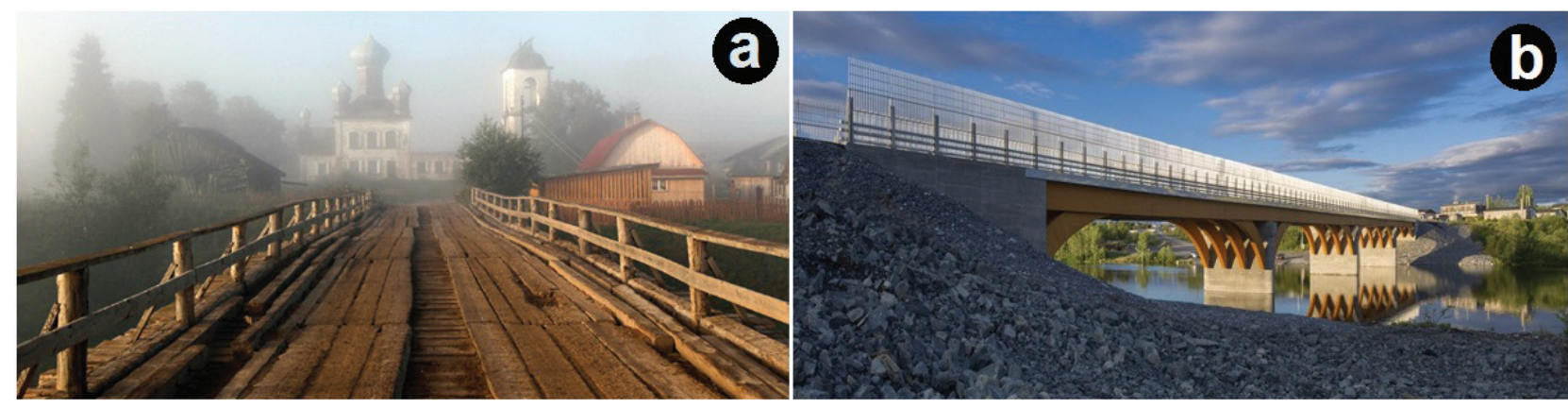

Figure 1: a. Wooden bridge in Kenozero National Park, Russia (Alexey Kudenko/RIA Novosti). b. Wooden bridge (160 m), designed with glulam beams in the Crie de Mistissini, Canada.

bridge beams led to the cost increase in railway production and was not always particularly reliable [21].

Owing to deforestation in the European part of the Russian Federation, bridge and transfer bars as well as sleepers made of solid wood have become scarce. Improvement of building structures raising their technical and economic performance is associated with the development of the new structural forms and effective types of joints and compounds, increased industrial production and the use of less expensive building materials. To solve these problems, it is recommended to use natural wooden materials in construction more extensively.

Increasing the production quality of wooden structures is associated with the development of complete factory produced sets of load-bearing structures for buildings as a whole when using a single technology for their manufacturing. However, the use of the existing assortment of sawn timber and traditional means of compound production leads to the increased labour input in the manufacture of structures and their installation due to the large number of assembly marks. Labour intensity could be reduced by decreasing the number of small-sized elements, which becomes possible when using composite wooden structures. In this respect, the problem of increasing the cross-section of wooden building elements when using sawn timber of limited assortment becomes quite relevant [24].

One of the ways to solve this problem is to use plates for combining wooden beams with cylindrical dowels, once proposed by the Kirov Polytechnic Institute, which makes it possible to obtain composite elements of high load-carrying capacity and low labour costs for their manufacture [25].

Owing to the introduction of new type of compounds of wooden structures based on the system of dowel plates, there is a need for an experimental and theoretical study of both the compounds themselves and the composite building elements for their operation under static and cyclic loads.

It is a common knowledge that in many cases, in addition to static load, construction structures are also subject to considerable dynamic loads [26]. These can be caused by vehicles, suspension, crane equipment, wind load, the impact of unbalanced mechanisms and so on. The impact of cyclic overload causes material fatigue of the structure, which can further lead to its destruction. In this case, failure can occur at a load much less than that obtained from static tests.

The efficiency of using modern steel connecting plates in the rallying of wooden beams in modern construction was already emphasised at the Conference of the International Council for Research and Documentation in Construction (Task Group CJ/w 18 A/TU 6) held in Russia in 1992 [21].

\section{Study of composite wooden bridge beams}

The low weight of the bridge itself, combined with smallscale traffic loads, means that the bridges are more slimline, lighter and more economical than bridges in other construction materials. To find out the resistance of joints of wooden bridge beams with incorporated dowel plates under cyclic influences, the laboratory of the Voronezh State Technical University has tested the fullscale samples of wooden composite bridges with dowel plates under the cyclic impacts.

An important factor that characterises the process of experimental determination of the limit of the samples endurance is choosing the test base. When studying the cyclic strength of the materials, various test bases are 
accepted. When testing wooden, stone and reinforced concrete elements for endurance, the $n_{0}=2 \cdot 10^{6}$ base of repeated loading cycles is usually adopted, which in the most cases corresponds to the real number of loads affecting building structures over the operational period [27].

It is also known that the endurance coefficient is significantly affected by the coefficient of asymmetry of the cycle referred to as $\rho$. Therefore, samples of wooden beams with the dowel plates were tested with asymmetry coefficient characteristic during the real operational mode. Basically, endurance tests were conducted without stopping the vibrator, in order to exclude the possible effect of the "rest mode" on endurance [26].

\section{Methodology}

For wooden building structures with suspended crane equipment, crane girders, span structures of conveyor and conveyor galleries, load-bearing bunker elements, overpasses, platforms for machines with rotating parts, sleepers, bridge bars and tower structures should be checked for wind impact, hoisting structures and power line supports - all the above should adopt structural schemes and types of connections of elements that ensure the rational use of the bearing capacity of wood for various types of stress condition and a minimum stress concentration, whereas accepted sections should be checked by calculation for endurance, determining the limit of endurance as follows: $\left(s_{\max }\right)[28,29]$.

Calculation of the bent elements of composite wooden structures with the dowel plates for endurance should be performed with repeated action of mobile, pulsating, vibrating or other types of load, causing a cyclic change in stress and fatigue phenomenon.

$$
\sigma_{\max }=\frac{M}{K_{w} \cdot W} \leq a_{\partial} \cdot R_{y} \cdot \gamma_{y},
$$

where $s_{\max }$ is the maximum stress in cross-sections, $M$ the calculated bending moment, $W$ the moment of resistance of the reduced cross-section and $K_{w}$ the coefficient that takes into account the effect of bonds' compliance at the moment of resistance, which is determined by the following formula:

$$
K_{w}=\left(1+m_{w} \frac{\Delta_{\hat{a}}}{\Delta}\right)^{-1},
$$

Table 1: Values of fatigue characteristics of wood $\left(R_{y}\right)$.

\begin{tabular}{lll}
\hline $\begin{array}{l}\text { Image of the stress- } \\
\text { ful element state }\end{array}$ & $\begin{array}{l}\text { Special } \\
\text { symbols } \\
\text { used }\end{array}$ & $\begin{array}{l}\text { Value of the calculated resis- } \\
\text { tance fatigue for first-grade } \\
\text { wood, } \mathrm{MPa}\end{array}$ \\
\hline $\begin{array}{l}\text { Bending along the } \\
\text { fibres }\end{array}$ & $R_{y}$ & 12.00 \\
$\begin{array}{l}\text { Compression along } \\
\text { fibres }\end{array}$ & $R_{y c o}$ & 12.00 \\
\hline
\end{tabular}

where $\mathrm{D}_{\mathrm{CB}}$ is normalized displacement of the ends, $\mathrm{D}$ the displacement of ends without bonds, and $m_{w}$ a parameter that depends on the geometric and mechanical characteristics of the material, which is determined by the formula:

$$
m_{w}=\left[\frac{E_{y} \cdot I_{\Pi p} \cdot h}{\left(\sum A_{y} \cdot I \cdot h\right)}\right]-1,
$$

where $E_{y}$ is the "fatigue modulus" of wood deformations, $E_{y}=0.8 E_{d}[21] ; E_{d}$ the modulus of elasticity of wood; $I_{n p}$ the moment of inertia of the integral cross-section; $I$ the moment of inertia of the element; $h$ the total height of the cross-section; $R_{y}$ the calculated resistance of "wood fatigue" during bending [22] (Table 1) and Yy the coefficient, taking into account the asymmetry of loading, which is determined by the following formula [23]:

$\gamma_{y}=1.02+1.55 \rho-0.92 \rho^{2}$

$a_{\partial}$ is the coefficient that takes into account the number of cycles and the frequency of loading and is determined by the formula:

$$
a_{\partial}=2.21-0.171 \mathrm{~g}\left(\frac{N}{w}\right)
$$

where $N$ is the number of cycles and $w$ the loading frequency.

The limit of endurance is the value of the maximum cycle voltage with the asymmetry coefficient $r$, corresponding to a specified number of $N$ cycles. The coefficient of asymmetry of the cycle is equal to the ratio of the minimum voltage vs. its maximum indicators [30].

To determine the limit of endurance for intermediate values of $r$, the following model is usually being constructed: the dependence of the endurance coefficient $\mathrm{K}_{E}$ is equal to the ratio of the endurance limit to the temporary resistance of the material $K_{t}$, based on the coefficient of the asymmetry of the loading cycle. 
Table 2: Comparison of the experimental and calculated values of the endurance factor.

\begin{tabular}{llll}
\hline No. & Determination method & \multicolumn{2}{l}{ Endurance factor at } \\
\cline { 3 - 4 } & & $\rho=0.20$ & $\rho=0.25$ \\
\hline 1 & Experimental & 0.459 & 0.470 \\
2 & Calculated & 0.451 & 0.475 \\
3 & Error, \% & -1.77 & +1.05 \\
\hline
\end{tabular}

As a rule, such dependence is represented by an equation of the first or $i$ order [31].

As a result of statistic processing of experimental data [21], obtained during testing of bent natural wooden elements with dowel plates installed for endurance, the equation of dependence of the endurance coefficient for the asymmetry coefficient was obtained in the following form [23]:

$$
K_{E}=\frac{\sigma_{\max }}{R_{E p}}=0.340+0.623 \cdot \rho-0.325 \cdot \rho^{2}
$$

\section{Results and discussions}

Figure 2 shows a graphical representation of the abovementioned interdependence and gives the points corresponding to the data of the experimental studies.

Table 2 gives the results of comparing the experimental and calculated values of the endurance factor.

The values of the endurance coefficient в $K_{E}^{N} \mathrm{~K}$ corresponding to $N=2$ million cycles for bent composite wooden elements with dowel plates can be determined by the following equation

$$
K_{E}^{N}=\frac{\sigma_{\max }}{R_{E p}}=1.075-0.072 \cdot \log N
$$

The value of the endurance factor cannot exceed the value of the coefficient of long-term resistance $m_{\text {long sop. }}=0.67$ [21, 22].

where $m_{\text {long sop. }}$ is the coefficient of long-term resistance. As a result of statistical processing of the experimental data, it was established that for $\rho=0.20 \ldots 0.60$ the inter-dependence $K_{E}^{N}$ with $r$ has the form:

$$
K_{E}^{N}=0.356+0.529 \cdot \rho
$$

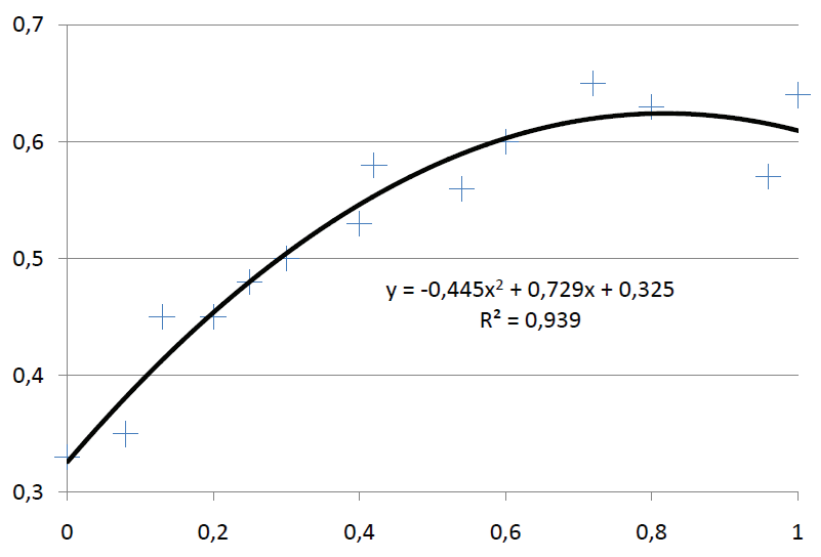

Figure 2: Dependence of the coefficient of endurance on the coefficient of the asymmetry of the loading cycle.

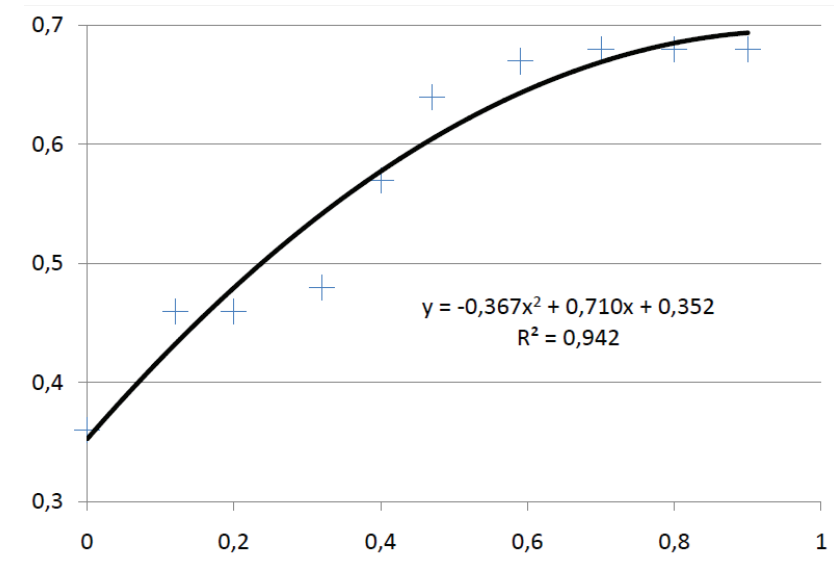

Figure 3: Dependence of the endurance coefficient corresponding to the number of loading cycles of $N=2$ million depending on the coefficient of the asymmetry of the loading cycle.

For $r=0.60 \ldots 1.00$, the dependence $K_{E}^{N}$ on $r$ is a straight line, which is parallel to the abscissa axis with ordinate $K_{E}^{N}=m_{\text {long sop. }}$ (Fig. 3).

Figure 3 shows that for practical engineering purposes, it is sufficient to know the value of the endurance limit or endurance coefficient, corresponding to the number of loading cycles of $N=2$ million $[21,30]$. Further increase in the number of cycles practically does not affect the performance characteristics of the structures.

Hence, when designing wooden composite elements with dowel plates designed for bending under conditions of prolonged cyclic loading, it is necessary to determine the dependence of the endurance coefficient $K_{\hat{a}}^{N}$ in $N$ figures, which corresponds to $N=2$ million cycles, based on the coefficient of the asymmetry of the loading cycle. 


\section{Conclusions}

- For the first time, experimental data on the endurance of composite wooden bridge beams have been obtained.

- Separate analysis has been made of the compounds under cyclic loading performance.

- The method has been developed for calculating the bent composite wooden bridge bars reinforced by the dowel plates under cyclic influences.

Acknowledgements: We express our deep gratitude to the head of the laboratory and the staff of the Department "Building Structures, Bases and Foundations named after Professor Yu. M. Borisov" of Voronezh State Technical University. We would also like to thank Pr. Savenko Viatcheslav Yakovitch and the anonymous reviewers for their valuable comments of the manuscript.

\section{References}

[1] Brozzetti, J. (2000). Design development of steel-concrete composite bridges in France. Journal of Constructional Steel Research, 55(1-3), 229-243.

[2] Pan, N.F. (2008). Fuzzy AHP approach for selecting the suitable bridge construction method. Automation in Construction, 17(8), 958-965.

[3] Demitz, J.R., Mertz, D.R., \& Gillespie, J.W. (2003). Deflection requirements for bridges constructed with advanced composite materials. Journal of Bridge Engineering, 8(2), 73-83.

[4] Demdoum, A., Hamed, Y., Feki, M., Hadji, R., Djebbar, M. (2015). Multi-tracer investigation of groundwater in El Eulma Basin (Northwestern Algeria), North Africa. Arabian Journal of Geosciences, 8(5), 3321-3333.

[5] Mokadem, N., Demdoum, A., Hamed, Y., Bouri, S., Hadji, R., et al. (2016). Hydrogeochemical and stable isotope data of groundwater of a multi-aquifer system: Northern Gafsa basin e Central Tunisia. Journal of African Earth Sciences, 114, 174-191.

[6] Raïs, K., Kara, M., Gadri, L., Hadji, R., Khochman, L. (2017). Original approach for the drilling process op-timization in open cast mines; case study of Kef Essenoun open pit mine Northeast of Algeria. Mining Science, 24, 147-159.

[7] Hamed, Y., Hadji, R., Redhaounia, B., Zighmi, K., Bâali, F., El Gayar, F. (2018). Climate impact on surface and groundwater in North Africa: a global synthesis of findings and recommendations. Euro-Mediterranean Journal for Environmental Integration.

[8] Besser, H., Mokadem, N., Redhaounia, B., Hadji, R., Hamad, A., Hamed, Y. (2018). Groundwater mixing and geochemical assessment of low-enthalpy resources in the geothermal field of southwestern Tunisia. Euro-Mediterranean Journal for Environmental Integration, 3, 16.

[9] Dahoua, L., Yakovitch, S.V., Hadji, R., Farid, Z. (2018). Landslide susceptibility mapping using analytic hierarchy process method in BBA-Bouira Region, case study of East-West Highway, NE Algeria. In: Recent Advances in Environmental Science from the Euro-Mediterranean and Surrounding Regions. Edited by A. Kallel, M. Ksibi, H. Ben Dhia, N. Khélifi. EMCEI 2017. Advances in Science, Technology \& Innovation (IEREK Interdisciplinary Series for Sustainable Development). Springer, Cham.

[10] Hadji, R., Boumazbeur, A., Limani, Y., Baghem, M., Chouabi, A. (2013). Geologic, topographic and climatic controls in landslide hazard assessment using GIS modeling: a case study of Souk Ahras region, NE Algeria. Quaternary International, 302, 224237.

[11] Hadji, R., Limani, Y., Demdoum, A. (2014). Using multivariate approach and GIS applications to predict slope instability hazard case study of Machrouha municipality, NE Algeria, 24-25 March 2014, IEEE Xplore.

[12] Zahri, F., Boukelloul, M., Hadji, R., Talhi, K. (2016). Slope stability analysis in open pit mines of Jebel Gustar career, Ne Algeria - a multi-steps approach. Mining Science, 23, 137-146.

[13] Dahoua, L., Savenko, V.Y., Hadji, R. (2017). GIS-based technic for roadside-slope stability assessment: an bivariate approach for A1 East-west highway, North Algeria. Mining Science, 24, 81-91.

[14] Mouici, R., Baali, F., Hadji, R., Boubaya, D., Audra, P., Fehdi, C.É., et al. (2017). Geophysical, geotechnical, and speleologic assessment for karst-sinkhole collapse genesis in Cheria plateau (NElgeria). Mining Science, 24, 59-71.

[15] Achour, Y., Boumezbeur, A., Hadji, R., Chouabbi, A., Cavaleiro, V., Bendaoud, E.A. (2017). Landslide susceptibility mapping using analytic hierarchy process and information value methods along a highway road section in Constantine, Algeria. Arabian Journal of Geosciences, 10, 194.

[16] Abdelouahad, M., Hadji, R., Fehdi, C. (2018). Use of slope failures inventory and climatic data for landslide susceptibility, vulnerability, and risk mapping in souk Ahras region. Mining Science, 24, 237-235.

[17] Zighmi, K., Hadji, R., Hamed, Y. (2018). GIS-based approaches for the landslide susceptibility prediction in Setif Region (NE Algeria). Geotechnical and Geological Engineering, 1-16.

[18] Hamed, Y., Ahmadi, R., Hadji, R., Mokadem, N., Ben Dhia, H., Ali, W. (2014). Groundwater evolution of the Continental Intercalaire aquifer of Southern Tunisia and a part of Southern Algeria: use of geochemical and isotopic indicators. Desalination and Water Treatment, 52(10-12), 1990-1996.

[19] Hamad, A., Baali, F., Hadji, R., Zerrouki, H., Besser, H., Mokadem, N., et al. (2018a). Hydrogeochemical characterization of water mineralization in Tebessa-Kasserine karst system (Tuniso-Algerian Transboundry basin). EuroMediterranean Journal for Environmental Integration, 3(1), 7.

[20] Hamad, A., Hadji, R., Bâali, F., Houda, B., Redhaounia, B., Zighmi, K., et al. (2018b). Conceptual model for karstic aquifers by combined analysis of GIS, chemical, thermal, and isotopic tools in Tuniso-Algerian transboundary basin. Arabian Journal of Geosciences, 11(15), 409.

[21] Boimatov, F.B. (1996). Endurance of joining of composite bridge wooden beams. Voronezh, VISI, 05.23.01.

[22] Prokofiev, A.S., Kabanov, V.A. (1981). About loading schemes for shear testing and evaluation of the stability of glued joints of wooden beams. Working capacity of building materials: Interuniversity. Sat./KISI, 30-32. 
[23] Belyankin, F.P. (1938). Influence of Asymmetric Load Cycles and Stress Concentration on the Strength of Wood Under Repeated Loads. Academy of Sciences of the Ukrainian SSR, Kiev, 36 p.

[24] Code of Regulations SP 64.13330.2011. (2011). Wooden constructions. The updated version of SNiP II-25-80 - M: Ministry of Regional Development of Russia, pp. 87.

[25] Forrest, P.G. (2013). Fatigue of Metals. Elsevier.

[26] Prokofiev, A.S., Kabanov, V.A,, Smorchkov, A.A. (1988). Design of Building Structures Taking into Account Fatigue. TPI, Tula, $106 \mathrm{p}$.

[27] Lam, F., Prion, H.G., He, M. (1997). Lateral resistance of wood shear walls with large sheathing panels. Journal of Structural Engineering, 123(12), 1666-1673.

[28] O'Sullivan, M.F., Ritchie, R.M. (1993). Tree stability in relation to cyclic loading. Forestry: An International Journal of Forest Research, 66(1), 69-82.

[29] Kobikov, G.A. (1957). Dynamic tests of a single-span wooden bridge from kleefaner beams. Proceedings of VIA, 122, 18-21.

[30] Shengelia, A.K., Znamensky, E.M., Prokofiev, A.S. (1986). Manual on the design of wooden structures. (to SNiP - II 25-80), p. 215.

[31] Prokofiev, A.S. (1985). Fatigue of wood. Izvestiya Vysshikh Uchebnykh Zavedenii. Construction and Architecture, 2, 18-21. 